\title{
Evaluating Success Factors of a Medication Adherence Tracker Pilot Program in Improving Part D Medication Adherence Metrics in a Medicare Advantage Plan: Importance of Provider Engagement
}

\author{
Minh Hong, PharmD; Tara Esse, PharmD, BCACP; Aisha Vadhariya, PhD; Esteban Gallardo, PharmD; \\ Maream Ashley Fosshat, PharmD; Jocelyne Mamvou, PharmD; Liana Bruce, PhD, MSPH; \\ Omar Serna, PharmD, BCACP; and Susan Abughosh, PhD
}

\begin{abstract}
BACKGROUND: Health plans and providers can increase quality by improving adherence to chronic disease medications included in star ratings among Medicare Advantage Part D (MAPD) plan enrollees. Research is needed to evaluate effective means of collaboration between health plans and providers. The Medication Adherence Tracker (MAT) is a health plan initiative to help primary care providers use outreach to improve their patients' adherence.

OBJECTIVE: To quantify the contribution of structural and process factors on the success of a health plan-initiated tracking system in improving chronic disease medication adherence over 6 months.

METHODS: The MAT quality improvement initiative was carried out in South Texas from June to December 2016. Health plan pharmacists used claims data to identify MAPD enrollees at risk of nonadherence to triple-weighted star medications: renin-angiotensin system antagonists, oral diabetes medications, and statins. Actionable reports were delivered biweekly to each provider, either by fax or in person, by embedded health plan nurses. Multivariable regression was used to evaluate sociodemographic and clinical factors as well as the role of provider outreach in increasing paid pharmacy claims and medication adherence as measured by proportion of days covered (PDC) $>0.8$.
\end{abstract}

RESULTS: 0 f 3,542 patients in 5 Texas physician-organized delivery system groups whose 67 providers received tracking reports from June through December 2016, 1,901 (54\%) patients had more than 1 related prescription, and $3,064(87 \%)$ received provider outreach on at least 1 prescription. $2,493(70 \%)$ had at least 1 paid pharmacy claim. Provider outreach was associated with greater likelihood of paid prescription claims (relative risk $[\mathrm{RR}]=4.59,95 \% \mathrm{Cl}=3.74-5.62)$ and greater year-end adherence $(\mathrm{PDC}>0.8$, $\mathrm{RR}=1.86,95 \% \mathrm{Cl}=1.63-2.12$ ) in multivariable predictive models. $95 \% \mathrm{Cls}$ for age, gender, low-income subsidy eligibility, and number of prescriptions did not exclude the null value.

CONCLUSIONS: Provider engagement is critical to effective health planprovider partnerships to overcome barriers, change behavior, and improve chronic disease care quality and population outcomes.

J Manag Care Spec Pharm. 2020;26(5):662-67

Copyright $\odot 2020$, Academy of Managed Care Pharmacy. All rights reserved.

\section{What is already known about this subject}

Medication adherence to hypertension, diabetes, and hyperlipidemia medications has been demonstrated to prevent and/or mitigate chronic disease among participants in Medicare Advantage Plans. Poor medication adherence is estimated to account for $10 \%$ of hospitalizations and 125,000 deaths in the United States per year. Health plans can conduct and measure the effectiveness of quality improvement interventions to improve medication adherence, sharing best practices for success factors.

\section{What this study adds}

Medication adherence tracking was identified as a successful way to address medication adherence in Medicare Advantage patients taking hypertension, diabetes, and hyperlipidemia medications.

Patients whose primary care providers (PCPs) provided outreach were more than 4.5 times as likely to have a paid prescription claim than those without, and nearly twice as likely to be classified as adherent (proportion of days covered >0.8) at the end of the year.

Our findings demonstrate that health plan pharmacists and nurses can work with PCP offices to improve chronic disease medication adherence.

$\mathrm{M}$ edication nonadherence continues to be one of the most challenging issues in improving health care. Poor medication adherence is estimated to contribute to $10 \%$ of hospitalizations as well as 125,000 deaths per year in the United States. ${ }^{1}$ Annual adjusted disease-specific economic costs of nonadherence ranged from $\$ 949$ to $\$ 44,190$ per patient according to a 2015 study, with estimated nondiseasespecific annual costs ranging from $\$ 5,271$ to $\$ 52,341 .^{2}$ In the United States, between $\$ 100-\$ 300$ billion in avoidable health care costs have been attributed to nonadherence annually, representing 3\%-10\% of total health care costs. ${ }^{3}$

From 2011 to 2014, the prevalence of U.S. adults aged 20 years and over with hypertension, diabetes, and high cholesterol was $33.5 \%, 12.6 \%$, and $12.1 \%$, respectively. ${ }^{4}$ Past 
research has shown that about half of all patients prescribed antihypertensive medications stop taking them within 1 year of the initial fill, and on any 1 day, patients omit about $10 \%$ of scheduled doses of medications. ${ }^{5}$ Higher adherence is traditionally defined as proportion of days covered (PDC) $>0.8$, or $80 \% .{ }^{6} \mathrm{PDC}$ is calculated by dividing days supply filled by the total number of treatment days in the population; for example, in a 6-month time period, if 3 out of 5 patients prescribed statins fill two 90-day-supply statin prescriptions each, but the other 2 patients fill only one 90-day-supply statin prescription each, the PDC for a population of 5 would be $[(3 \times 2 \times 90)+(2 \times 1 \times 90)] \div(5 \times 2 \times 90)=0.80$. Health plan customers with higher adherence rates to antihypertensive medications were found to be more likely to achieve blood pressure control compared with those with medium to lower levels of adherence. In addition, each incremental 25\% increase in PDC for statin medications has been linked to a 3.8 milligramper-deciliter reduction in low-density lipoprotein cholesterol. ${ }^{7}$ Chronic disease medication adherence also plays a central role in the Centers for Medicare \& Medicaid Services (CMS) Star Rating System for Medicare Advantage Part D (MAPD) plans. This rating system evaluates performance on a set of quality measures. Plans receive a composite quality star rating on a scale from 1 to 5, with 4-5 stars indicating high quality, which renders them eligible to receive additional quality bonus payments. The payments can be used to provide extra benefits and lower premiums for enrollees. ${ }^{8}$ Star ratings are critical for accountability as well as the enhancement of customer choice, and a plan's overall score is impacted by 3 MAPD tripleweighted medication adherence metrics: adherence to hypertension, diabetes, and cholesterol medications. In 2016, these metrics accounted for approximately $30 \%$ of Part D star ratings and $11 \%$ of the overall MAPD ratings. ${ }^{8}$ Plans are thus devoting time and resources into improvement focused on chronic disease medication adherence.

While evaluations of patient outreach programs have documented success via phone, text, or multimodal contact, research is needed to evaluate how health plans and providers can most effectively collaborate to improve population-wide medication adherence. ${ }^{9-14}$ Our organization implemented the Medication Adherence Tracker (MAT) initiative in a MAPD population in areas of South Texas identified for improvement. Our primary objective was to assess the contribution of outreach by primary care providers (referred to as "providers" henceforth) in addition to clinical, demographic, and process factors in the success of the tracking initiative on increasing paid pharmacy claims and chronic disease medication adherence.

\section{Methods}

This study involved analysis of secondary data collected during the tracking initiative, which comprised a collaborative quality improvement effort between an MAPD and 67 of its in-network-contracted physicians operating in 5 physicianorganized delivery systems (PODS) in South Texas. The 5 practice regions comprised the Middle, North, South, Northwest, and West Rio Grande Valley. The initiative was piloted in June 2016 in 1 region, then rolled out roughly every 2 weeks until all 5 regions were implementing the processes by the end of August 2016. The study protocol was reviewed and approved by the University of Houston Institutional Review Board.

Figure 1 shows the criteria used to target the analytic sample of 3,542 individuals for whom at least 1 late refill was recorded for the list of triple-weighted MAPD chronic disease (hypertension, diabetes, or hyperlipidemia) maintenance medications for which PDC is calculated for MAPD plans, including reninangiotensin system antagonists, oral (noninsulin) diabetes medications, and cholesterol medications (statins). The full methodology for calculation of PDC, including the programming code for weighting and computation of these specific medications via claims data, is detailed by the Centers for Disease Control Training and Technical Assistance Support Center. ${ }^{15}$

Patients excluded for lack of prescription drug coverage did not have data in the health plan claims database but may have obtained their medications through Veterans Affairs. Every 2 weeks, health plan clinical pharmacists generated the targeted tracking reports with data for all patients identified within each practice and sent them to on-site health plan nurses assigned to providers in the 5 PODS. Nurses printed and distributed reports to provider offices, requesting that providers contact their patients to discuss adherence within 3 weeks.

Providers or their staff were responsible for taking action on the reports, and how they preferred to conduct outreach was at their discretion. Outreach included patient office visits, phone calls to identify barriers to adherence, and calling in 90-day prescription refills (vs. 30-day) to the patient's pharmacy. Provider outreach was coded for analysis as "yes" if a patient received outreach from their provider's office on any prescription over the 6-month time frame observed.

Provider offices completed and returned tracking reports to the health plan 3 weeks later with detailed outreach documentation. After integrating and cross-checking these data against pharmacy claims, the health plan clinical pharmacy team ascertained the dichotomous outcome variable of at least 1 paid prescription claim over the observation period.

The second outcome variable analyzed, year-end PDC, was calculated at the end of the 2016 calendar year as the mean PDC for all medications in any of the 3 disease states, regardless of which medication had originally triggered inclusion in the analytic sample. To calculate PDC, the number of days the patient was covered by at least 1 drug in the target drug class is counted based on prescription fill date and days supply. The number of covered days is then divided by the number of days 

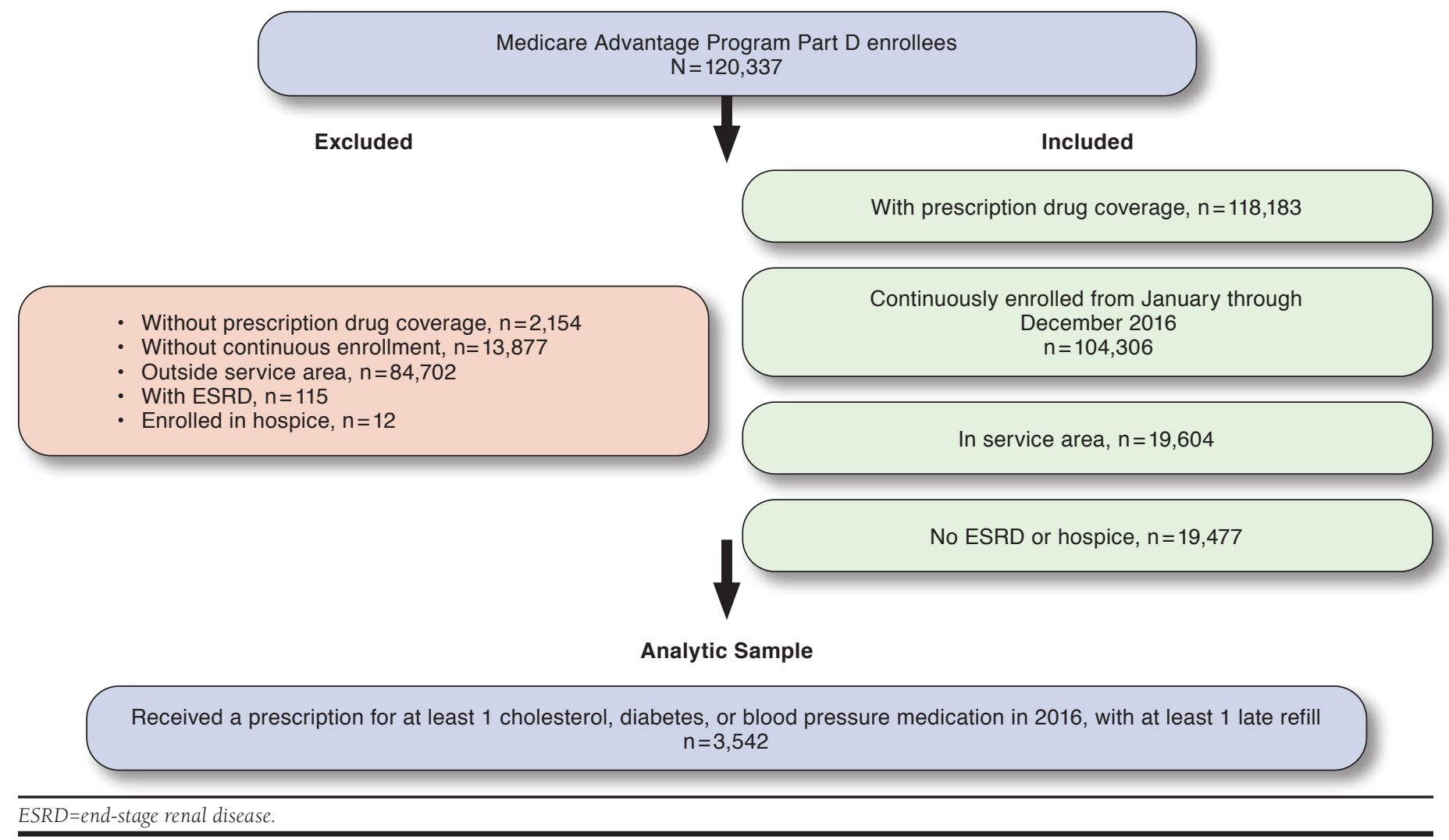

in the measurement period. Full replicable instructions for PDC calculations are given in Medication Adherence Measure Calculations of the Medicare-Medicaid Plan Performance Data Technical Notes. ${ }^{16}$

Patient demographic and clinical characteristics including age, gender, low-income subsidy (LIS) status, and days supply of medication were obtained from baseline reports before each PODS entry in the tracking program. Days supply ranged from 0 to $>90$ days but was not ultimately used as a separate predictor variable because of its role in calculating PDC. Total number of different prescriptions per individual (dichotomized as $>1$ prescription vs. just 1 ) was also included as a proxy for disease severity.

Multivariable regression models were fit to assess relative contributions of clinical and demographic covariates, plus the process variable of provider outreach, on the dichotomous outcomes of at least 1 paid claim and year-end PDC. The outcome events were not rare, so relative risks were calculated using log-linked binomial modeling for paid pharmacy claims and dichotomously coded ending PDC $>0.8$. All statistical analyses were performed with an a priori alpha criterion of 0.05 using SAS 9.3 software (SAS Institute, Cary, NC).

\section{Results}

A total of 3,542 patients were included in the 2016 MAT initiative, with 3,064 (87\%) receiving provider outreach (Table 1). Median age was 70 years (interquartile range 67-76). The majority of patients had a 90-day supply at baseline (78\%), were not LIS eligible (89\%), and were female (52\%). Of the 3,064 patients who did receive provider outreach, $97 \%$ had a paid prescription claim as compared with only $3 \%$ of the 478 who did not receive provider outreach. Proportions receiving provider outreach across physician group regions also varied in direct relation to both outcomes $\left(P<0.05, \chi^{2}\right.$-test), with the highest proportion of paid claims in the Northwest Rio Grande Valley group (76\%) and the lowest (49\%) in the West Rio Grande Valley group.

As shown in Table 1, adjusting for other covariates, those who received provider outreach were more likely to have a paid pharmacy claim compared with those who did not receive provider outreach (relative risk $[\mathrm{RR}]=4.59,95 \% \mathrm{CI}=3.74-5.62$ ). Patients with providers in the South ( $R R=0.83,95 \% \mathrm{CI}=0.77$ 0.89), Northwest ( $R R=1.14,95 \% C I=1.08-1.20)$, and West Rio Grande Valley PODS ( $R R=0.64,95 \% \mathrm{CI}=0.54-0.76)$ were less likely to have a paid pharmacy claim as compared with the 


\begin{tabular}{|c|c|c|c|c|}
\hline \multirow{2}{*}{$\begin{array}{l}\text { Characteristic } \\
\text { Age in years, median (25th-75th percentile) }\end{array}$} & \multicolumn{2}{|c|}{$\begin{array}{c}\text { Total } \\
(\mathrm{N}=3,542)\end{array}$} & $\begin{array}{c}\text { Paid Claim Model } \\
\text { Relative Risk (95\% CI) }\end{array}$ & $\begin{array}{c}\text { Ending PDC }>0.8 \text { Model } \\
\text { Relative Risk }(95 \% \mathrm{CI})\end{array}$ \\
\hline & 70.0 & $(67.0-76.0)$ & $1.00 \quad(1.00-1.00)$ & $1.00 \quad(1.00-1.01)$ \\
\hline \multicolumn{5}{|l|}{ Gender, n (\%) } \\
\hline Female & 1,842 & $(52)$ & $1.03 \quad(0.99-1.08)$ & $1.00 \quad(0.94-1.07)$ \\
\hline Male & 1,700 & $(48)$ & (referent) & (referent) \\
\hline \multicolumn{5}{|l|}{ LIS eligible, n (\%) } \\
\hline Yes & 388 & $(11)$ & $1.06 \quad(0.99-1.12)$ & $1.00 \quad(0.90-1.10)$ \\
\hline No & 3,154 & (89) & (referent) & (referent) \\
\hline \multicolumn{5}{|l|}{ Number of prescriptions per individual, $\mathrm{n}(\%)$} \\
\hline$>1$ & 1,901 & $(54)$ & $0.66 \quad(0.63-0.69)$ & $0.63 \quad(0.59-0.67)$ \\
\hline 1 & 1,641 & $(46)$ & (referent) & (referent) \\
\hline \multicolumn{5}{|c|}{ Geographic location of PODS in Rio Grande Valley, n (\%) } \\
\hline Middle & 1,191 & (34) & (referent) & (referent) \\
\hline North & 648 & (18) & $1.04 \quad(0.98-1.11)$ & $0.89 \quad(0.82-0.97)$ \\
\hline South & 802 & $(23)$ & $0.83 \quad(0.77-0.89)$ & $(0.65-0.78)$ \\
\hline Northwest & 742 & $(21)$ & $1.14 \quad(1.08-1.20)$ & $(0.84-1.00)$ \\
\hline West & 159 & (4) & $0.64 \quad(0.54-0.76)$ & $(0.58-0.83)$ \\
\hline \multicolumn{5}{|l|}{ Provider conducted outreach, n (\%) } \\
\hline Yes & 3,064 & $(87)$ & $4.59 \quad(3.74-5.62)$ & $(1.63-2.12)$ \\
\hline No & 478 & (13) & & \\
\hline \multicolumn{5}{|l|}{ At least 1 paid pharmacy claim, n (\%) } \\
\hline Yes & 2,493 & $(70)$ & - & - \\
\hline No & 1,049 & (30) & & \\
\hline \multicolumn{5}{|l|}{ Year-end PDC, n (\%) } \\
\hline$\geq 80 \%$ & 1,780 & $(50)$ & - & - \\
\hline$<80 \%$ & 1,762 & $(50)$ & & \\
\hline
\end{tabular}

referent Middle Rio Grande Valley PODS. Those who received provider outreach were also more likely to be adherent as measured by $>80 \%$ year-end PDC compared with those who did not receive provider outreach $(\mathrm{RR}=1.86,95 \% \mathrm{CI}=1.63$ 2.12). Patients with providers in the North, South, and West Rio Grande Valley as well as those with more than 1 prescription $(\mathrm{RR}=0.63,95 \% \mathrm{CI}=0.59-0.67)$ were also less likely to be adherent by the end of the year. In models for both outcomes, LIS eligibility was not significantly associated for either outcome in the presence of adjustment for PODS. Sensitivity analyses adjusting for clustering, repeated observations, and month of each PODS tracking initiation did not significantly vary the findings.

\section{Discussion}

The MAPD triple-weighted adherence star measures have resulted in a growing focus on medication adherence for chronic conditions. In order to ensure optimal patient care, implementation insights are needed to ensure there are quality improvement initiatives for medication adherence. ${ }^{17,18}$ Our findings indicated that among 3,542 patients targeted for a tracking program over a 6-month observation period, provider outreach is a key success factor to improving patients' medication adherence over 6 months.

Our findings were consistent with existing research showing that physician communication is significantly and positively correlated with patient adherence, supporting the theory that active provider engagement improves adherence. ${ }^{18}$ This may be because the value, familiarity, and trust among patients and their providers and office staff should be harnessed in order to improve adherence rates. Our experience combined with interpretation of these findings also suggests that strong clinical leadership to encourage lagging providers may help, as well as collaboration and partnership for ongoing efforts by health plans, providers, and patients. Seabury et al. (2014) identified the need to align payer, provider, and patient incentives to promote medication adherence ${ }^{19}$; this effort must take into account adherence barriers. ${ }^{17,20}$ It is noteworthy that the LIS eligibility status covariate was not significant in the multivariable model that included provider outreach, suggesting that actively engaged providers conducting outreach may be able to overcome social determinants of health-related barriers. 
Further research with detailed social determinants of health data would be needed to explore this theory.

Our findings indicated that patients with providers in the South, Northwest, and West Rio Grande Valley PODS were less likely to have paid pharmacy claims for chronic disease medications, as compared with their Middle Rio Grande Valley counterparts. Although numerous factors could have explained the geographic differences (including proximity to Mexico, where prescriptions could have been obtained south of the border), the Middle Rio Grande Valley had a health plan pharmacist on site as well as a provider that was a highly engaged champion of the initiative. Presence of an on-site pharmacist could also be examined as a potentially important process variable in future studies.

Star measures have become a central theme for clinical and managed care decision makers. Future research should also consider other factors like copays and access/region-specific variables (for example, proximity to a foreign country border). Initiatives to track adherence and keep providers accountable are well worth the effort in data collection, tracking, and continuous quality improvement efforts. Pharmacists also contribute by educating and counseling on the importance of adherence. However, the value of familiarity and trust in providers is central to chronic disease medication adherence efforts. Findings observed from the MAT initiative demonstrate the value of provider outreach by contacting patients to identify and address barriers to adherence.

We recommend multipronged communication strategies that include electronic monitoring. ${ }^{21}$ In addition, we recommend prescribing 90-day supplies for maintenance therapies, as this can help ensure the medications are in the patient's possession and can encourage adherence. Using pharmacy claims data from a large national pharmacy chain, Taitel et al. (2012) noted that both medication adherence and persistence were 20\% and 23\% higher, respectively, for patients who received a 90 -day supply when compared with a group that only received a 30-day supply. ${ }^{22}$ It is also important to note that initiatives like MAT are only effective when continued; nonadherence results when adherence interventions are stopped. ${ }^{21}$

\section{Limitations}

This study has some limitations to consider. One limitation is that provider offices varied in the way they preferred to act on reports; the type of outreach was left to their discretion and may have been inconsistently documented. However, the inclusion of region in the multivariable model was intended to help control for clustering of patients within provider groups operating at the same facilities.

Verification of medication adherence was also a challenge, as pharmacy claims were chosen as the only validation method to confirm medication possession, not actual ingestion of the medication. Taitel et al. noted the same limitation in their study, stating that although the use of pharmacy claims is a standard method for evaluation of medication adherence, it is "only a proxy for actual medication use."22 As a result, the lack of direct observation may overinflate medication adherence rates, especially in the 90-day group.

Medication discontinuation can also potentially overinflate medication adherence rates. According to Fairman and Matheral (2000), if patients discontinue medication before the supply of their last claim runs out, even if the medication was substituted, the current length of therapy will change..$^{23}$ Thus, the PDC rate would change. However, we were not able to capture this information to the level of specificity needed to adequately control for this type of limitation.

\section{Conclusions}

Our findings imply that provider engagement to conduct outreach with their patients was a key success factor of 1 health plan's tracking initiative to improve adherence to chronic disease medications in a MAPD population. Future studies should employ controlled study designs with additional process variables to further understand successful program implementation. Improving adherence is a preventive health effort that requires interdisciplinary collaboration and engagement at the provider, health plan, and patient level with continuous, ongoing quality improvement. Ideally, health plans, providers, and patients will all operate toward the common goal of improving adherence.

\section{Authors}

MINH HONG, PharmD; MAREAM ASHLEY FOSSHAT, PharmD; JOCELYNE MAMVOU, PharmD; TARA ESSE, PharmD, BCACP; ESTEBAN GALLARDO, PharmD; and OMAR SERNA, PharmD, BCACP, CareAllies, Houston, Texas. LIANA BRUCE, PhD, MSPH, Cigna Health and Life Insurance Company and Lundy-Fetterman School of Business, Campbell University, Buies Creek, North Carolina. AISHA VADHARIYA, PhD, and SUSAN ABUGHOSH, PhD, University of Houston College of Pharmacy, Houston, Texas.

AUTHOR CORRESPONDENCE: Liana D. Bruce, PhD, Visiting Professor of Healthcare Management, Lundy-Fetterman School of Business, Campbell University, Buies Creek, NC 27506. Tel.: 410.972.7776; E-mail: lbruce@campbell.edu.

\section{DISCLOSURES}

This study was funded by Cigna. The manuscript was prepared as a work for hire. Hong, Esse, Gallardo, Serna, Fosshat, and Mamvou are employees of CareAllies, a Cigna company. Bruce was employed by Cigna at the time of the study. Vadhariya reports a past internship at Regeneron Pharmaceuticals, unrelated to this work. Abughosh reports grants from Regeneron Pharmaceuticals, Valeant Pharmaceuticals, Sanofi, and BMS/ Pfizer, unrelated to this work. 


\section{ACKNOWLEDGMENTS}

The authors gratefully acknowledge the funding provided for this study by Cigna as well as the technical and editorial assistance provided by Dr. Stuart Lustig.

\section{REFERENCES}

1. Viswanathan M, Golin CE, Jones CD, et al. Interventions to improve adherence to self-administered medications for chronic diseases in the United States: a systematic review. Ann Intern Med. 2012;157(11):785-95.

2. Cutler RL, Fernandez-Llimos F, Frommer M, Benrimoj C, GarciaCardenas V. Economic impact of medication non-adherence by disease groups: a systematic review. BMJ Open. 2018;8(1):e016982.

3. Mack KA, Zhang K, Paulozzi L, Jones C. Prescription practices involving opioid analgesics among Americans with Medicaid, 2010. J Health Care Poor Underserved. 2015;26(1):182-98.

4. National Center for Health Statistics. Health, United States, 2016: With Chartbook on Long-term Trends in Health. Hyattsville, MD: National Center for Health Statistics; 2017.

5. Vrijens B, Vincze G, Kristanto P, Urquhart J, Burnier M. Adherence to prescribed antihypertensive drug treatments: longitudinal study of electronically compiled dosing histories. BMJ. 2008;336(7653):1114-17.

6. Bramley TJ, Gerbino PP, Nightengale BS, Frech-Tamas F. Relationship of blood pressure control to adherence with antihypertensive monotherapy in 13 managed care organizations. J Manag Care Pharm. 2006;12(3):239-45. Available at: https://www.jmcp.org/doi/10.18553/jmcp.2006.12.3.239.

7. Ho PM, Rumsfeld JS, Masoudi FA, et al. Effect of medication nonadherence on hospitalization and mortality among patients with diabetes mellitus. Arch Intern Med. 2006;166(17):1836-41.

8. Goggins KM, Wallston KA, Nwosu S, Schildcrout JS, Castel L, Kripalani S. Health literacy, numeracy, and other characteristics associated with hospitalized patients' preferences for involvement in decision making.J Health Commun. 2014;19(Suppl 2):29-43.

9. Abughosh SM, Wang X, Serna O, et al. A pharmacist telephone intervention to identify adherence barriers and improve adherence among nonadherent patients with comorbid hypertension and diabetes in a Medicare Advantage plan. J Manag Care Spec Pharm. 2016;22(1):63-73. Available at: https://www.jmcp.org/doi/10.18553/jmcp.2016.22.1.63.

10. Foreman KF, Stockl KM, Le LB, et al. Impact of a text messaging pilot program on patient medication adherence. Clin Ther. 2012;34(5):1084-91.

11. Leslie RS, Gilmer T, Natarajan L, Hovell M. A multichannel medication adherence intervention influences patient and prescriber behavior. J Manag Care Spec Pharm. 2016;22(5):526-38. Available at: https://www.jmcp.org/ doi/10.18553/jmcp.2016.22.5.526.
12. Marquez Contreras E, Vegazo Garcia O, Martel Claros N, et al. Efficacy of telephone and mail intervention in patient compliance with antihypertensive drugs in hypertension. ETECUM-HTA study. Blood Press. 2005;14(3):151-58.

13. Pandey A, Krumme A, Patel T, Choudhry N. The impact of text messaging on medication adherence and exercise among postmyocardial infarction patients: randomized controlled pilot trial. JMIR Mhealth Uhealth. 2017;5(8):e110.

14. Solomon DH, Iversen MD, Avorn J, et al. Osteoporosis telephonic intervention to improve medication regimen adherence: a large, pragmatic, randomized controlled trial. Arch Intern Med. 2012;172(6):477-83.

15. Centers for Disease Control Training and Technical Assistance Support Center; National Center for Chronic Disease Prevention and Health Promotion. Calculating proportion of days covered (PDC) for antihypertensive and antidiabetic medications: an evaluation guide for grantees. August 31, 2015. Available at: https://www.cdc.gov/dhdsp/docs/Med-AdherenceEvaluation-Tool.pdf. Accessed April 6, 2020.

16. Centers for Medicare \& Medicaid Services. 2016 Part C \& D star ratings measures. Available at: https://www.cms.gov/Medicare/Prescription-DrugCoverage/PrescriptionDrugCovGenIn/Downloads/2016_Star_Ratings_ Measure List.pdf. Accessed April 6, 2020

17. Gellad WF, Grenard JL, Marcum ZA. A systematic review of barriers to medication adherence in the elderly: looking beyond cost and regimen complexity. Am J Geriatr Pharmacother. 2011;9(1):11-23.

18. Zolnierek KB, Dimatteo MR. Physician communication and patient adherence to treatment: a meta-analysis. Med Care. 2009;47(8):826-34.

19. Seabury SA, Gupta CN, Philipson TJ, Henkhaus LE. Understanding and overcoming barriers to medication adherence: a review of research priorities. J Manag Care Pharm. 2014;20(8):775-83. Available at: https://www.jmcp.org/ doi/10.18553/jmcp.2014.20.8.775.

20. Hincapie AL, Taylor AM, Boesen KP, Warholak T. Understanding reasons for nonadherence to medications in a Medicare Part D beneficiary sample. J Manag Care Spec Pharm. 2015;21(5):391-99. Available at: https:// www.jmcp.org/doi/10.18553/jmcp.2015.21.5.391.

21. van Heuckelum M, van den Ende CHM, Houterman AEJ, Heemskerk CPM, van Dulmen S, van den Bemt BJF. The effect of electronic monitoring feedback on medication adherence and clinical outcomes: a systematic review. PLoS One. 2017;12(10):e0185453.

22. Taitel M, Fensterheim L, Kirkham H, Sekula R, Duncan I. Medication days' supply, adherence, wastage, and cost among chronic patients in Medicaid. Medicare Medicaid Res Rev. 2012;2(3):mmrr.002.03.a04.

23. Fairman KA, Matheral B. Evaluating medication adherence: which measure is right for your program? J Manag Care Pharm. 2000;6(6):499-506. Available at: https://www.jmcp.org/doi/10.18553/jmcp.2000.6.6.499. 